HIV

\title{
HIV status of sexual partners is more important than antiretroviral treatment related perceptions for risk taking by HIV positive MSM in Montreal, Canada
}

\author{
J Cox, J Beauchemin, R Allard
}

Sex Transm Infect 2004;80:518-523. doi: 10.1136/sti.2004.011288

See end of article for authors' affiliations

......

Correspondence to: Joseph Cox, 1301 Sherbrooke Street East, Montreal, Quebec, H2L 1 M3 Canada; jcox@ santepub-mtl.qc.ca

Accepted for publication 9 September 2004

\begin{abstract}
Objective: To examine the role of antiretroviral treatment related perceptions relative to other clinical and psychosocial factors associated with sexual risk taking in HIV positive men who have sex with men (MSM). Methods: Participants were recruited from ambulatory HIV clinics in Montreal. Information on sociodemographic factors, health status, antiretroviral treatment related perceptions, and sexual behaviours was collected using a self administered questionnaire. At-risk sexual behaviour was defined as at least one occurrence of unprotected insertive or receptive anal intercourse in the past 6 months. Multivariate logistic regression was performed to evaluate the associations between at-risk sexual behaviour and covariates.

Results: 346 subjects participated in the study. Overall, $34 \%$ of subjects were considered at risk; $43 \%$ of sexually active subjects $(n=274)$. At-risk sexual behaviour was associated with two antiretroviral treatment related perceptions: (1) taking antiretroviral treatment reduces the risk of transmitting HIV (adjusted odds ratio (OR), 2.10; $95 \%$ confidence interval (Cl), 1.16 to 3.80); and (2) there is less safer sex practised by MSM because of HIV treatment advances (OR, 1.82; $\mathrm{Cl}, 1.14$ to 2.90$)$. Other factors, however, were more strongly associated with risk. These were: (1) safer sex fatigue (OR, 3.23; $\mathrm{Cl}, 1.81$ to 5.78$)$; (2) use of "poppers" during sexual intercourse $(\mathrm{OR}, 6.28 ; \mathrm{Cl}, 2.43$ to 16.21); and (3) reporting a greater proportion of HIV positive anal sex partners, compared with reporting no HIV positive anal sex partners: (a) $<50 \%$ HIV positive (OR, 16.79; $\mathrm{Cl}, 4.70$ to 59.98$)$; (b) $\geqslant 50 \%$ HIV positive $(\mathrm{OR}, 67.67 ; \mathrm{Cl}, 15.43$ to 296.90).

Conclusion: Despite much emphasis on HIV treatment related beliefs as an explanation for sexual risk taking in MSM, this concern may play a relatively minor part in the negotiation of risk by HIV positive MSM. Serosorting, safer sex fatigue, and the use of poppers appear to be more important considerations in understanding the sexual risk behaviours of HIV positive MSM.
\end{abstract}

$M$ en who have sex with men (MSM) continue to be one of the populations most affected by HIV infection. In the United States during 1999-2002, 42\% of incident HIV cases were in MSM and the percentage of incident HIV cases annually increased by $17 \%$ over this time. ${ }^{1}$ High rates of new HIV infection in MSM continue to be observed in some Canadian cities. ${ }^{2}$ Since 2000, a cohort study of MSM in Montreal observed an increase in annual HIV incidence from 0.43 to 0.83 per 100 person years overall. Although this increase was not statistically significant, during the same time period there was a $20 \%$ increase in unprotected receptive anal sex. ${ }^{3}$ This return to less safer sex in the HIV negative MSM population has also been documented in other jurisdictions. ${ }^{45}$ In addition, increases in the incidences of other sexually transmitted infections (STIs) such as rectal gonorrhoea and infectious syphilis have been documented. ${ }^{4-7}$

Antiretroviral medications for the treatment of HIV have been available for more than a decade. The positive impact of highly active antiretroviral therapy (HAART) on morbidity and mortality has been well described. ${ }^{8}$

Several researchers have proposed a link between HAART and the at-risk sexual behaviours of MSM. ${ }^{5}{ }^{10}$ It has been suggested that HAART might increase sexual practices that lead to transmission of HIV and other STIs. That is, as a result of HAART, HIV negative MSM are less concerned about contracting HIV, HIV positive MSM are less concerned about transmitting it, and both groups are more likely to engage in unsafe sex, resulting in more HIV infection. ${ }^{11}$
The literature on this topic is equivocal for both HIV negative, ${ }^{912}$ and HIV positive MSM. ${ }^{42-16}$ Regardless, the hypothesis of "treatment optimism" as the reason for observed at-risk behaviours of HIV positive MSM has received a great deal of attention. ${ }^{12} 141617$ A recent review of determinants of at-risk sexual behaviours for people living with HIV, however, highlights the numerous psychological, social, interpersonal, as well as treatment related factors associated with risk taking. ${ }^{18}$

There are good epidemiological and clinical reasons to study the role of antiretroviral treatment related perceptions relative to the sexual risk behaviours of HIV positive MSM. MSM are thought of as a sentinel population in a constantly changing epidemic and as such may experience or exhibit changes in risk behaviours first. Also, primary HIV resistance $^{19}$ and HIV "superinfection" have been identified as important and potentially disastrous consequences of at-risk sexual behaviours. ${ }^{20}$ Recent trends in the occurrence of rectal gonorrhoea and syphilis among both HIV negative and HIV positive MSM further justify efforts to better understand this issue. $^{72122}$ Clearly, a definition of at-risk sexual behaviours which includes risk for transmission to others as well as acquisition of treatment resistant virus and other STIs is warranted.

Abbreviations: HAART, highly active antiretroviral therapy; MSM, men who have sex with men; STls, sexually transmitted infections 


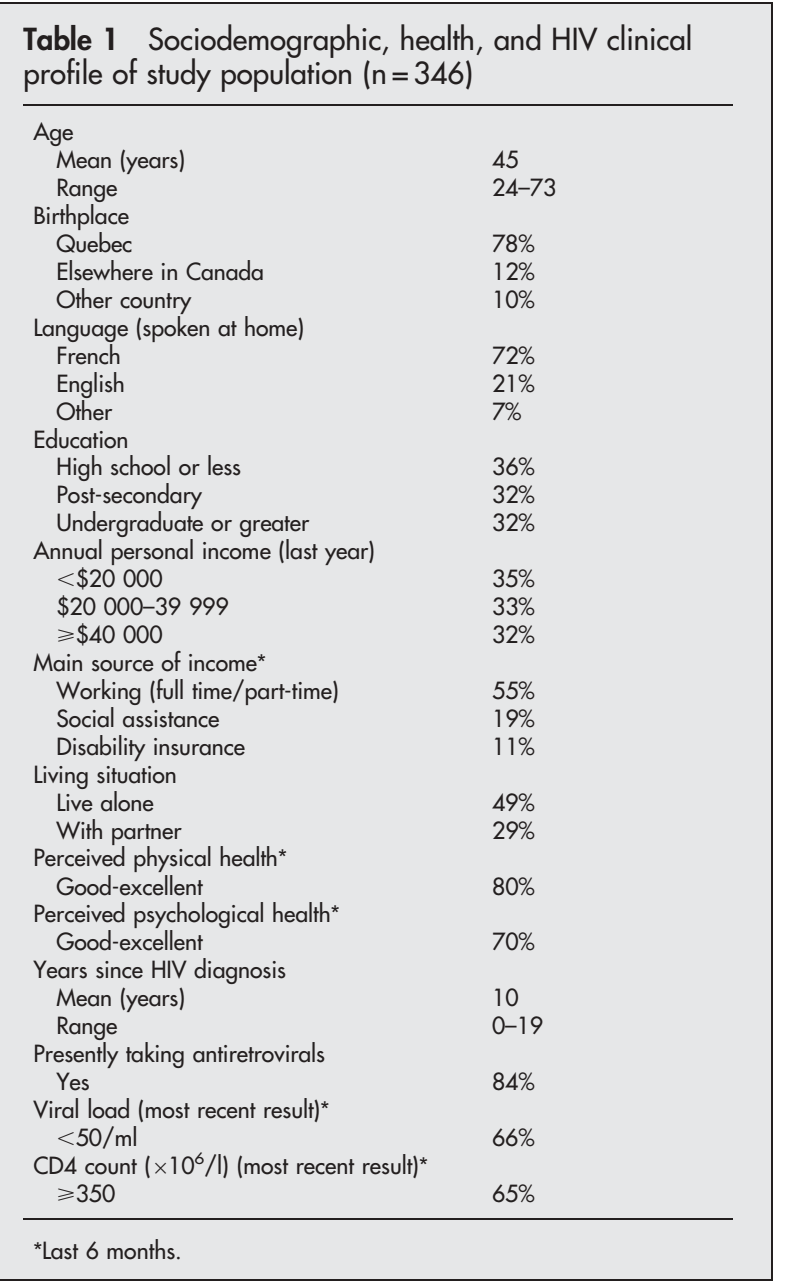

In this study, we examined the role of antiretroviral treatment related perceptions on at-risk sexual behaviours of HIV positive MSM. Other factors were also considered, including sociodemographic, clinical and treatment experience, health and wellbeing, sexual preferences, drug use, HIV prevention beliefs, and interpersonal and social factors.

\section{METHODS}

Data collection used a self administered questionnaire distributed to HIV positive MSM attending five ambulatory HIV clinics in Montreal. Clinic based recruitment was chosen because most HIV positive MSM in Montreal are thought to have regular medical follow up. To participate, subjects had to be 18 years or older, MSM, HIV positive, and read English or French.

A comprehensive survey instrument was developed for this study. It was based on the AIDS Risk Reduction Model. ${ }^{17}{ }^{23}$ As such, a variety of clinical and psychosocial factors thought important to sexual behaviours were considered. Also, validated scales related to this topic were used to inspire questionnaire development. ${ }^{172425}$ We went through several iterations of the instrument. To optimise content and ecological validity, the questionnaire was reviewed by a group of experts made up of psychosocial and behavioural researchers in the field of HIV-AIDS, clinicians, and representatives of organisations serving HIV positive individuals and/or MSM. The instrument was also pretested with a subset of the study population and adjusted for length, wording (face validity), and acceptability on sensitive issues. The final questionnaire contained over 400 items and 19 psychosocial scales and took approximately 1 hour to complete.

Subjects were asked about sexual practices during the previous 6 months. Information was collected on the type (regular and casual) and number of sex partners, whether insertive or receptive anal sex had occurred, condom use, as well as HIV serostatus of anal sex partners. Various measures were taken to increase study participation and representativeness of the sample. Subjects were recruited directly through clinicians and nurses, who were instructed to systematically give the study materials (study brochure and integrated consent questionnaire booklet) to their HIV positive MSM patients independently of health status or prescribed therapies. Recruitment was done over a 5 month period (October 2002-February 2003) to assure the sample did not exclude patients requiring less intensive medical follow up, giving a greater clinical spectrum of the HIV positive MSM population. The recruitment sites represented both public and private providers and serve a large portion of the HIV positive MSM population in Montreal. A total of 688 questionnaire packages were distributed.

Potential participants were asked to review the study materials at their leisure; there was no requirement to decide at that moment. These materials clearly stated the study goals and contents of the questionnaire and that participation was entirely voluntary and anonymous. For patients who had additional questions or concerns about the study, they could ask clinic personnel directly or call the research coordinator whose name and telephone number were listed on the consent form. Subjects were required to date the consent as an indication they had read and understood the information. Participants received a \$C10 gift certificate which was attached to the questionnaire booklet. Booklets were to be returned to the Montreal Public Health Department using pre-addressed postage paid envelopes, preferably within 1 week. The study protocol and questionnaire were reviewed and approved by the McGill University Faculty of Medicine institutional review board.

Statistical analyses were done using SPSS version 11.0. Principal components factor analyses were done to confirm a priori defined scales. Scale psychometric properties, percentage variance explained, and internal consistency (Cronbach's alpha) were ascertained. ${ }^{26}$ The psychometric properties and elements of these scales are available from the authors.

At-risk sexual behaviour was defined as at least one occasion of insertive and/or receptive anal sex without a condom in the past 6 months. The identification of potential covariates was done using univariate logistic regression analyses; only those variables associated at the $p \leqslant 0.15$ level were examined further in the multivariate logistic regression model. In addition, all the antiretroviral treatment related perception variables were forced into the model because these were integral to the research question. A backward stepwise method was used to identify factors associated with at-risk sexual behaviours. ${ }^{27}$ The strength of the associations between variables was assessed using odds ratios (OR). Confidence intervals (CI) for OR were also calculated and reported.

\section{RESULTS}

A total of 346 questionnaires were returned, representing a $50 \%$ response overall. This represents the proportion of subjects who were given the consent questionnaire booklet and who later decided to respond by completing and returning the booklet. Subjects were asked to complete a short non-response form when they did not wish to complete the questionnaire. Unfortunately, too few forms were received so we cannot comment on the profile of nonparticipants. 
Table 2 Clinical and psychosocial factors associated with sexual risk takingt in HIV positive MSM, univariate logistic regression analyses $(n=346)$

\begin{tabular}{|c|c|c|c|}
\hline & p Value & OR & $95 \% \mathrm{Cl}$ \\
\hline \multicolumn{4}{|l|}{ Sociodemographic factors } \\
\hline Age $^{*}$ (younger) & $<0.001$ & 1.07 & 1.04 to 1.10 \\
\hline Born outside the province of Quebec, Canada & 0.137 & 1.49 & $0.88,2.53$ \\
\hline Language spoken at home (French $v$ English, other) & 0.091 & 0.65 & 0.40 to 1.07 \\
\hline Living alone & 0.026 & 0.60 & 0.38 to 0.94 \\
\hline Education (Undergraduate or greater) & 0.031 & 1.66 & 1.05 to 2.62 \\
\hline $\begin{array}{l}\text { Main source of incomeł (full/part-time work v social security, } \\
\text { disability, pension, other) }\end{array}$ & 0.003 & 2.00 & 1.26 to 3.15 \\
\hline \multicolumn{4}{|l|}{ Annual personal income $(\div \$ 1000)$, last year } \\
\hline$<20$ & & 1 & - \\
\hline $20-39$ & 0.015 & 2.07 & 1.15 to 3.71 \\
\hline$\geqslant 40$ & $<0.001$ & 3.06 & 1.71 to 5.47 \\
\hline \multicolumn{4}{|l|}{ Clinical markers and treatment experience } \\
\hline Year of HIV diagnosis* (more recent diagnosis) & 0.013 & 1.06 & 1.01 to 1.11 \\
\hline Ever taken antiretrovirals (yes) & 0.141 & 2.31 & 0.76 to 7.04 \\
\hline Presently taking antiretrovirals (yes) & 0.556 & 1.20 & 0.65 to 2.20 \\
\hline Year first started antiretrovirals* (more recently on antiretroviral) & 0.003 & 1.10 & 1.03 to 1.16 \\
\hline Viral load $(<50 / \mathrm{ml})$ on most recent testł & 0.448 & 0.83 & 0.51 to 1.34 \\
\hline CD4 count $(\geqslant 350)$ on most recent test & 0.161 & 1.42 & 0.87 to 2.31 \\
\hline Protease inhibitor containing antiretroviral regimen & 0.006 & 0.52 & 0.33 to 0.83 \\
\hline $\begin{array}{l}\text { Nucleoside reverse transcriptase inhibitor exclusive antiretroviral } \\
\text { regimen }\end{array}$ & 0.049 & 1.95 & 1.00 to 3.80 \\
\hline Adherence to antiretroviral regimen (all pills, last 7 days) & 0.824 & 1.06 & 0.64 to 1.74 \\
\hline Number and severity of symptoms due to antiretrovirals $\ddagger^{*}$ & 0.871 & 1.00 & 0.98 to 1.02 \\
\hline \multicolumn{4}{|l|}{ Health and wellbeing indicators } \\
\hline Perceived physical health $\ddagger$ (good to excellent) & 0.908 & 1.03 & 0.59 to 1.81 \\
\hline Perceived psychological health $\ddagger$ (good to excellent) & 0.175 & 0.71 & 0.44 to 1.16 \\
\hline Depressive symptoms and anxiety $\ddagger^{*}$ & 0.144 & 1.22 & 0.94 to 1.58 \\
\hline Limitations on activities daily life $\neq$ (often to very often) & 0.879 & 0.96 & 0.55 to 1.66 \\
\hline Perceived severity of worsening HIV disease* & 0.355 & 1.17 & 0.84 to 1.62 \\
\hline $\begin{array}{l}\text { Perceived susceptibility to worsening HIV disease* } \\
\text { Treatment related perceptions }\end{array}$ & 0.316 & 0.88 & 0.68 to 1.13 \\
\hline Importance of antiretrovirals to personal health and wellbeing* & 0.012 & 0.76 & 0.61 to 0.94 \\
\hline $\begin{array}{l}\text { Treatment optimism (HIV/AIDS less frightening, controllable, } \\
\text { almost over)* }\end{array}$ & 0.599 & 1.07 & 0.82 to 1.40 \\
\hline HIV pos people taking antiretrovirals live longer than those who don' $t^{*}$ & 0.060 & 1.27 & 0.99 to 1.63 \\
\hline Less safer sex practised by MSM because of treatment advances* & 0.008 & 1.38 & 1.09 to 1.74 \\
\hline $\begin{array}{l}\text { There is greater acceptance of HIV pos people and social integration } \\
\text { because of treatment advances* }\end{array}$ & 0.920 & 0.99 & 0.76 to 1.29 \\
\hline Antiretroviral treatment reduces the risk of transmitting $\mathrm{HIV}^{*}$ & 0.221 & 1.18 & 0.91 to 1.53 \\
\hline Less worry in having unprotected sex because of PEP* & 0.059 & 1.35 & 0.99 to 1.83 \\
\hline \multicolumn{4}{|l|}{ Sexual preferences and drug use } \\
\hline Sexual sensation seeking* & $<0.001$ & 1.59 & 1.25 to 2.01 \\
\hline Satisfaction with sex life* $\ddagger$ & $<0.001$ & 1.51 & 1.26 to 1.81 \\
\hline Alcohol during sexual relations $\ddagger$ (at least once) & $<0.001$ & 3.10 & 1.95 to 4.92 \\
\hline "Poppers" during sexual relationsł (at least once) & $<0.001$ & 5.34 & 3.30 to 8.65 \\
\hline Viagra during sexual relationsł (at least once) & $<0.001$ & 2.71 & 1.55 to 4.74 \\
\hline Cocaine during sexual relations $\ddagger$ (at least once) & 0.002 & 3.23 & 1.53 to 7.09 \\
\hline \multicolumn{4}{|l|}{ Beliefs and attitudes towards HIV prevention } \\
\hline Safer sex fatigue* & $<0.001$ & 1.91 & 1.50 to 2.42 \\
\hline $\begin{array}{l}\text { Having unprotected receptive anal sex is less risky than having } \\
\text { unprotected insertive anal sex }\end{array}$ & $<0.001$ & 3.27 & 2.04 to 5.22 \\
\hline $\begin{array}{l}\text { Less important to protect self/others against HIV transmission/ } \\
\text { re-infection and other STI* }\end{array}$ & $<0.001$ & 3.00 & 2.12 to 4.26 \\
\hline Less personal responsibility in preventing the spread of $\mathrm{HIV}^{*}$ & $<0.001$ & 2.87 & 1.97 to 4.18 \\
\hline Less anticipated regrets if unprotected insertive anal sex with an & 0.002 & 1.46 & 1.15 to 1.86 \\
\hline HIV negative partner* & & & \\
\hline \multicolumn{4}{|l|}{ Interpersonal/contextual/social factors } \\
\hline Having had at least one regular sex partner $\ddagger$ & $<0.001$ & 3.65 & 2.19 to 6.09 \\
\hline Having had at least one casual sex partner & $<0.001$ & 5.39 & 3.09 to 9.38 \\
\hline Having met at least one new sexual partner in a saunał & $<0.001$ & 4.73 & 2.91 to 7.67 \\
\hline \multicolumn{4}{|l|}{ Proportion of HIV positive anal sex partnersł } \\
\hline $0 \%$ & & 1 & - \\
\hline$<50 \%$ & $<0.001$ & 18.49 & 8.32 to 41.08 \\
\hline$\geqslant 50 \%$ & $<0.001$ & 13.10 & 6.29 to 27.25 \\
\hline Experience of discrimination, rejection for being HIV pos* & 0.779 & 1.03 & 0.83 to 1.29 \\
\hline Fear of disclosure, others finding out ${ }^{\star}$ & 0.185 & 1.14 & 0.94 to 1.38 \\
\hline Friends knowing about your HIV status (none to a few) & 0.125 & 1.42 & 0.91 to 2.22 \\
\hline Having someone to confide in & 0.818 & 1.10 & 0.48 to 2.52 \\
\hline Having someone that can help/instrumental support & 0.840 & 1.08 & 0.53 to 2.17 \\
\hline Having someone close, affectionate/emotional support & 0.819 & 1.09 & 0.54 to 2.19 \\
\hline Feeling isolated or alone (never or rarely) $\ddagger$ & 0.550 & 0.95 & 0.79 to 1.13 \\
\hline Satisfaction with social life ${ }^{*}$ & 0.063 & 0.84 & 0.71 to 1.01 \\
\hline
\end{tabular}

"Continuous variable. All others are binary except "Annual personal income" and "Proportion of HIV positive anal sex partners."

†At least one occurrence of unprotected anal sex during the last 6 months †During the last 6 months 
The response proportion varied across clinics, ranging from $34 \%$ to $75 \%$. Subjects did not differ significantly between sites with regard to age, education, income, employment, perceived physical and psychological health, number of years since HIV diagnosis, and at-risk sexual behaviour.

The sociodemographic, health, and HIV clinical profile of the sample is presented in table 1 . The average age was 45 years and $72 \%$ of subjects reported speaking French at home, reflecting Montreal's linguistic make-up. Almost one third $(29 \%)$ of subjects had been diagnosed with HIV infection since 1996. Eighty four per cent of subjects were currently taking antiretrovirals and an additional 10\% had previously taken antiretrovirals but had stopped at the time of data collection. Overall, $62 \%$ of subjects with a history of antiretroviral treatment rated their experience as somewhat positive to very positive.

Seventy nine per cent of subjects were sexually active, having had at least one sexual partner during the past 6 months. Over two thirds $(68 \%)$ of all subjects had at least one new sexual partner, while $36 \%$ had six or more. In total, $56 \%(\mathrm{n}=194)$ reported having insertive and/or receptive anal sex: $27 \%(n=93)$ had anal sex with at least one HIV positive partner and $29 \%(n=101)$ had anal sex with no known HIV positive partner (HIV negative or HIV unknown partners only). Three out of four subjects (72/93) who had anal sex with one or more HIV positive partners reported at least one incident of unprotected anal sex (21\% of the total sample), while less than half (45/101) of those subjects with no known HIV positive partners did so (13\% of the total sample). Overall, $34 \%$ of participants were defined as having at-risk sexual behaviours.

Univariate analyses helped identify potential covariates of at-risk sexual behaviour (table 2). While most clinical and health indicators were not associated with risk, a variety of other factors including several antiretroviral treatment related perceptions were.

Multivariate logistic regression modelling identified two antiretroviral treatment related perceptions associated ( $p$ $<0.05$ ) with at risk sexual behaviour: (1) taking antiretroviral treatment reduces the risk of transmitting HIV; and (2) there is less safer sex practised by MSM because of HIV treatment advances (table 3 ). In addition, younger age, more recent initiation of antiretroviral treatment, higher annual income, satisfaction with sex life, dissatisfaction with social life, safer sex fatigue, less importance attributed to protecting self and others against HIV transmission/re-infection and other STIs, use of "poppers" during sex, and greater proportion of HIV positive anal sex partners were all significantly $(p<0.05)$ associated with risk.

Although on univariate analysis, the belief "antiretroviral treatment reduces the risk of transmitting HIV" was not significantly associated with at-risk behaviour (OR, 1.18; 95\% CI, 0.91 to 1.53 ), its presence in the multivariate model suggests negative confounding by one or more of the other variables in the model. Even though none of these other variables by itself has the same effect on the OR, removing from the model either income or proportion of HIV positive anal sex partners (or both) brings the OR back almost to its univariate value and level of significance. We infer from this that the confounding involves a combination of several variables, including these two.

\section{DISCUSSION}

Recent developments in our efforts to control the HIV epidemic highlight the importance of considering determinants of at-risk sexual behaviours in HIV positive people. A principal tenet of the Serostatus Approach to Fighting the Epidemic (SAFE) calls for the expedient evaluation and support of newly HIV diagnosed people. In this way appropriate care and prevention services may be provided. ${ }^{28}$ Recently, the Centers for Disease Control and Prevention published recommendations on how to integrate prevention for HIV positive people in the clinical setting. ${ }^{29}$ Much work needs to be done before clinic based prevention programmes are widely implemented. The development of these programmes will be guided by research on the numerous and diverse factors thought to influence the sexual behaviours of HIV positive people. ${ }^{18}$ Similarly, the definition of at-risk sexual behaviours must move beyond the conventional consideration of HIV positive people as a public health threat-that is, HIV transmission to HIV negative or serostatus unknown sexual partners. Specifically, risk should also reflect the possibility of acquisition of antiretroviral resistant HIV and other STIs. For this study, we chose to measure risk as any unprotected anal sex regardless of the serostatus of sexual partners. Using this measure, 34\% of HIV positive MSM were found to have had at-risk sexual behaviour. Still, this measure does not include the risk of

Table 3 Multivariate logistic regression model* of factors associated with at-risk sexual behaviour of HIV positive MSM $(n=249)$

\begin{tabular}{|c|c|c|}
\hline & Adjusted OR & $95 \% \mathrm{Cl}$ \\
\hline Age (younger) & 1.06 & 1.00 to 1.13 \\
\hline \multicolumn{3}{|l|}{ Annual personal income $(\div \$ 1000)$} \\
\hline$<20$ & 1 & - \\
\hline $20-39$ & 8.47 & 2.41 to 29.80 \\
\hline$\geqslant 40$ & 14.51 & 4.09 to 51.46 \\
\hline \multicolumn{3}{|l|}{ Year first started antiretrovirals (more recently on } \\
\hline antiretrovirals) & 1.18 & 1.05 to 1.32 \\
\hline Less satisfaction with social life & 1.62 & 1.09 to 2.42 \\
\hline More satisfaction with sex life & 1.61 & 1.07 to 2.41 \\
\hline $\begin{array}{l}\text { Antiretrovirals treatment reduces the risk of transmitting HIV } \\
\text { Less safer sex practised by MSM because of HIV treatment }\end{array}$ & 2.10 & 1.16 to 3.80 \\
\hline advances & 1.82 & 1.14 to 2.90 \\
\hline \multicolumn{3}{|l|}{ Less important to protect self/others against HIV } \\
\hline transmission/re-infection and other STI & 2.18 & 1.13 to 4.24 \\
\hline Safer sex fatigue & 3.23 & 1.81 to 5.78 \\
\hline Use of "poppers" during sex & 6.28 & 2.43 to 16.21 \\
\hline \multicolumn{3}{|l|}{ Proportion of HIV positive anal sex partners } \\
\hline $0 \%$ & 1 & \\
\hline$<50 \%$ & 16.79 & 4.70 to 59.98 \\
\hline$\geqslant 50 \%$ & 67.67 & 15.43 to 296.90 \\
\hline
\end{tabular}


acquisition of STIs which can be transmitted through other types of unprotected contact.

In the multivariate logistic regression analysis, at-risk sexual behaviours were strongly associated with the use of poppers during sexual relations, safer sex fatigue, and less importance given to protecting oneself and others from STIs/ HIV. Increased at-risk sexual behaviour in the context of drug use during sex has consistently been reported for both HIV negative and positive MSM. ${ }^{7031}$ Whether or not the use of poppers influenced the use of condoms cannot be known. Poppers (alkyl nitrites) are often taken by MSM to enhance anal sphincter relaxation and pleasure during receptive anal sex. In this way, the association may well be an indicator of receptive anal sex. Preliminary analyses showed a significant association between at-risk behaviours and the belief that having unprotected receptive anal sex is less risky than having unprotected insertive anal sex (table 2). Likewise, a sense of fatigue regarding the self control and vigilance needed to maintain safer sex as well as one's commitment to practise safer sex have been found to influence risk. ${ }^{14}$

At-risk HIV positive MSM were more likely to report being more satisfied with their sex life and less satisfied with their social life. Additional analyses are necessary to explore this apparent paradox. Having more social support, however, has been found to decrease risk taking in HIV negative MSM. ${ }^{32}$ The relation between risk taking and satisfaction with one's sex life is less clear. Perhaps it suggests condomless anal sex is more satisfying and reflects a more carefree attitude towards sex and prevention. Preliminary analyses of our data indicate satisfaction with sex life is associated with having casual partners, meeting new sex partners in saunas, and using Viagra.

Most importantly, our findings suggest that HIV positive MSM adopt different risk management strategies when having sex with known HIV positive partners. Whether HIV positive MSM engaging in unprotected anal sex between themselves consider this to be risky is unsure. The practice of serosorting (selecting seroconcordant partners) has been described for both HIV positive and negative men. ${ }^{33-35}$

While no association was found between self reported undetectable viral load and risk taking, the belief that HAART protects against transmitting HIV was an important determinant of unprotected anal sex. These findings are consistent with a recent meta-analysis of research on this topic. ${ }^{36}$ The scale used in our study had component questions such as "An HIV positive men with undetectable viral load is unlikely to transmit HIV" and "My antiretrovirals decrease the risk that I infect someone else". This positive association between atrisk sexual behaviours and perceived favourable impact of antiretrovirals on HIV transmission was also found in an international collaboration study of HIV optimism among homosexual men. ${ }^{12}$

However, when considered simultaneously with a variety of clinical, psychosocial, and contextual factors, antiretroviral treatment related perceptions were found to play a relatively minor part in the at-risk sexual behaviours of participants in this study. Only two of the eight scales used to measure the impact of antiretroviral treatments were significantly associated with the risk measure.

The results of this study are also interesting for what was not found, compared to other studies. For example, there was no association between risk taking and psychological distress, ${ }^{37}$ sexual sensation seeking, ${ }^{38}$ and HIV clinical factors such as undetectable viral load, ${ }^{4}$ and the presence of a protease inhibitor as part of the antiretroviral regimen. ${ }^{15}$ Perhaps our more comprehensive examination of the issue of antiretroviral treatment related perceptions and sexual risk taking, while simultaneously looking at a variety of health,
Key messages

- Evaluating the at-risk sexual behaviours of HIV positive MSM requires the careful consideration of a variety of clinical and psychosocial factors. Information on these determinants can help guide the development of prevention programmes

- HIV positive MSM were more likely to be at risk if they believed that "antiretroviral treatment reduces the risk of transmitting HIV" and that "there is less safer sex practised by MSM because of HIV treatment advances"

- The most important factor for risk taking by HIV positive MSM was having had a greater proportion of HIV positive sexual partners among all anal sex partners in the past 6 months. Other significant determinants were younger age, higher personal income, more recent start of antiretrovirals, having a greater sense of safer sex fatigue, and using poppers during sexual intercourse

- At-risk sexual behaviour in this population may lead to HIV transmission and acquisition of antiretroviral treatment resistant HIV (superinfection) and other sexually transmitted infections

psychosocial, contextual, and behavioural factors allowed for greater confounder control.

There are several study limitations. Because of the $50 \%$ participant response proportion we cannot exclude a selection bias. Also, sexual behaviour was self reported; however, the anonymous nature of the questionnaire likely reduced participant concerns about confidentiality and response bias. The cross sectional design of this study also limits any assertion of a temporal or causal relation between the identified determinants and at-risk sexual behaviours.

At-risk HIV positive MSM in this study were more likely to have HIV positive sexual partners. As such, they were at greater risk for acquisition of antiretroviral resistant HIV and STIs. These findings suggest that HIV positive MSM may view these outcomes as less concerning especially since they are already HIV positive. The treatable nature of STIs and lacking evidence on the harms of superinfection probably contribute to these beliefs.

How do we use this information to develop sexual health and prevention programmes for HIV positive MSM? Our study findings support a comprehensive approach to evaluating sexual risk behaviours in HIV positive MSM. Care providers must consider a variety of factors including the serostatus of sexual partners, patient perceptions regarding the impact of antiretroviral treatments on transmissibility, and feelings of HIV prevention fatigue.

\section{ACKNOWLEDGEMENTS}

We would like to acknowledge the contribution of study participants and study recruitment sites: Clinique L'Actuel, Clinique du Quartier Latin, the Immunodeficiency Service of the Royal Victoria Hospital, Immune Deficiency Treatment Centre of the Montreal General Hospital, and Clinique Lori. Also, we wish to recognise the contribution of Yannick Dion, Marie-Eve Girard, Samara Dalfen, and Michele Lalonde. Production of this research has been made possible through a financial contribution from Health Canada and the Montreal Public Health Department. The views expressed herein do not necessarily represent the views of Health Canada or the Montreal Public Health Department. 


\section{CONTRIBUTORS}

JC and JB designed and implemented the study; RA provided input regarding study design and sample size estimation; all authors participated in the analysis of data and interpretation of study results; JC was the lead author on the manuscript; JB and RA assisted in editing and finalising the initial and revised manuscripts.

\section{Authors' affiliations}

J Cox, J Beauchemin, R Allard, Montreal Public Health Department, Montreal, Canada

J Cox, J Beauchemin, R Allard, National Institute of Public Health of Quebec, Montreal, Canada

J Cox, Immune Deficiency Treatment Centre, Montreal General Hospital, McGill University Health Centre, Montreal, Canada

J Cox, R Allard, McGill University, Montreal, Canada

Conflict of interest: None.

Ethical approval: The study protocol and questionnaire were reviewed and approved by the McGill University Faculty of Medicine Institutional Review Board.

\section{REFERENCE}

1 Centers for Disease Control and Prevention. Increases in HIV Diagnoses-29 States, 1999-2002. Morb Morty Wkly Rep 2003;52:1 145-8.

2 Calzavara LM, Burchell AN, Major C, et al. Increases in HIV incidence among men who have sex undergoing repeat diagnostic HIV testing in Ontario, Canada. AIDS 2002:16:1655-61.

3 Remis RS, Alary M, Otis J, et al. Trends in HIV incidence and sexual behaviour in a cohort of men who have sex with men (MSM) in Montreal, 1996-2003. Can J Infect Dis 2004; 15(Suppl A):54A.

4 Dukers NHTM, Goudsmit J, de Wit J, et al. Sexual risk behaviour relates to the virological and immunological improvements during highly active antiretroviral therapy in HIV-1 infection. AIDS 2001;15:369-78.

5 Centers for Disease Control and Prevention. Increases in unsafe sex and rectal gonorrhea among men who have sex with men-San Francisco, California, 1994-1997. Morb Mort Wkly Rep 1999:48:45-8.

6 Lambert G, Paquette N, Toussaint MC, et al. Syphilis-information aux professionnels. 2003. Ávailable at www.santepub-mtl.qc.ca/Mi/syphilis/ syphilis 12072003.html. Accessed August 122004

7 Ciesielski C. Sexually transmitted diseases in men who have sex with men: An epidemiologic review. Curr Infect Dis Rep 2003:5:145-52.

8 Tassie J-M, Grabar S, Lancar R, et al. Time to AIDS from 1992 to 1999 in HIV1 -infected subjects with known date of infection. J Acquir Immune Defic Syndr 2002;30:81-7.

9 Elford J, Bolding G, Sherr L. High-risk sexual behaviour increases among London gay men between 1998 and 2001: what is the role of HIV optimism? AIDS 2002;16:1537-44.

10 Dilley J, Woods W, McFarland W. Are advances in treatment changing views about high-risk sex? N Engl J Med 1997;337:501-2

11 Katz M, Schwarcz S, Kellogg T, et al. Impact of highly active antiretroviral treatment on HIV seroincidence among men who have sex with men: San Francisco. Am J Public Health 2002;92:388-94.

12 International Collaboration on HIV Optimism. HIV treatments optimism among gay men: An international perspective. J Acquir Immune Defic Syndr 2003:32:545-50.

13 McGowan JP, Shah SS, Ganea CE, et al. Risk behavior for transmission of human immunodeficiency virus (HIV) among HIV-seropositive individuals in an urban setting. Clin Infect Dis 2004;38:122-7.

14 Ostrow D, Fox K, Chmiel J, et al. Attitudes towards highly active antiretroviral therapy are associated with sexual risk taking among HIV-infected and ininfected homosexual men. AIDS 2002;16:775-80.

15 Diclemente R, Funkhousser E, Wingwood G, et al. Protease inhibitor combination therapy and decreased condom use among gay men. South Med J 2002;95:421-5.
16 Holmes W, Pace J. HIV-seropositive individuals optimistic beliefs about prognosis and relation to medication and safe sex adherence. J Gen Intern Med 2002; 17:677-83.

17 Vanable P, Ostrow D, McKirnan D, et al. Impact of combination therapies on HIV risk perceptions and sexual risk among HIV-positive and HIV-negative gay and bisexual men. Health Psychol 2000;19:134-45.

18 Crepaz N, Marks G. Towards an understanding of sexual risk behavior in people living with HIV: a review of social, psychological, and medical findings. AIDS 2002;16:135-49.

19 Little SJ, Holte S, Routy J-P, et al. Antiretroviral-drug resistance among patients recently infected with HIV. N Engl J Med 2002;347:385-94.

20 Yerly S, Jost S, Monnat $M$, et al. Prevalence of co- and super-infection in IVDUs. Antiviral Ther 2003;8(Suppl 1):S203.

21 Centers for Disease Control and Prevention. Primary and secondary syphilis among men who have sex with men-New York City, 2001. Morb Mort Wkly Rep 2002;51:853-6.

22 Giard M, Queyron PC, Ritter J, et al. The recent increase of syphilis cases in Lyon University Hospitals is mainly observed in HIV-infected patients: descriptive data from a laboratory-based surveillance system. J Acquir Immune Defic Syndr 2003:34:441-3.

23 Catania J, Kegeles S, Coates T. Towards an understanding of risk behavior: an AIDS risk reduction model (ARRM). Health Educ $Q$ 1990; 17:53-72.

24 Calzavara L, Burchell A, Remis R, et al. Delayed application of condoms is a risk factor for human immunodeficiency virus infection among homosexual and bisexual men. Am J Epidemiol 2003;157:210-17.

25 Craib K, Martindale S, Chan K, et al. Relationship between HIV optimism and sexual risk behaviour in a cohort of gay men in Vancouver: evidence of complacency? Can J Infect Dis 2001;12(Suppl B):323.

26 Kline P. An easy guide to factor analysis. London: Routledge, 1994.

27 Hosmer DW Jr, Lemeshow S. Applied logistic regression. New York: John Wiley \& Sons, 1989.

28 Janssen RS, Holtgrave DR, Valdiserri RO, et al. The serostatus approach to fighting the HIV epidemic: prevention strategies for infected individuals. Am J Public Health 2001;91:1019-24.

29 Centers for Disease Control and Prevention. Incorporating HIV prevention into the medical care of persons living with HIV. Morb Mort Wkly Rep 2003;52(RR-12).

30 Ackers $M$, Greenberg A, Lin C, et al. High HIV incidence among men who have sex with men participating in an HIV vaccine efficacy trial, United States, 1998-2002. 11th Conference on Retrorviruses and Opportunistic Infections, 2004. Available at www.retroconference.org/2004/cd/Abstract/857.htm. Accessed August 122004.

31 Koblin B, Chesney M, Husnik M, et al. High-risk behaviors among MSM in 6 US cities: Baseline data from the EXPLORE study. Am J Public Health 2003;93:926-32

32 Strathdee S, Hogg RS, Martindale SL, et al. Determinants of sexual risk-taking among young HIV-negative gay and bisexual men. J Acquir Immune Defic Syndr Human Retrovir 1998;19:61-6.

33 Wolf K, Young J, Rickenback M, ef al. Prevalence of unsafe sexual behavior among HIV-infected individuals: The Swiss HIV cohort study. J Acquir Immune Defic Syndr 2003:33:494-9.

34 McConnell J, Grant R. Sorting out serosorting with sexual network methods. 10th conference on retroviruses and opportunistic infections Oral Presentation \#41. 2003. Available at www.retroconference.org/2003/Abstract/ Abstract.aspx?AbstractlD = 1449. Accessed August 122004 .

35 Truong HM, McFarland W, Kellogg T, et al. Increases in "serosorting" may prevent further expansion of the HIV epidemic among MSM in San Francisco. 11 th Conference on Retrorviruses and Opportunistic Infections Poster 843. 2004. Available at ww.retroconference.org/2004/cd/Abstract/843.htm. Accessed August 122004

36 Crepaz N, Hart TA, Marks G. Highly active antiretroviral therapy and sexual risk behavior. JAMA 2004;292:224-36.

37 Clement U. Psychological correlates of unprotected intercourse among HIVpositive gay men. J Psychol Human Sex 1992;5:133-55.

38 Kalichman S, Weinhardt L, DiFonzo K, et al. Sensation seeking and alcohol use as markers of sexual transmission risk behavior in HIV-positive men. Ann Behav Med 2002:24:229-35. 